\title{
Radical Polymerization of 2,4,5-Tribromostyrene
}

\author{
Tsutomu Oishi, ${ }^{\dagger}$ Haruyuki HoriE*, and Hideo Shuyama* \\ Department of Applied Chemistry and Chemical Engineering, \\ Yamaguchi University, 2557 Tokiwadai, Ube 755, Japan \\ * Chemical Research Laboratory, TOSOH Corporation, \\ 4560 Kaisei-cho, Sinnanyo 746, Japan
}

(Received November 17, 1992)

\begin{abstract}
The initial polymerization rate equations $\left(R_{\mathrm{p}}=k[\mathrm{M}]^{m}[\mathrm{I}]^{n}\right)$ of $2,4,5$-tribromostyrene (TBS) in toluene and in dioxane were determined at $60^{\circ} \mathrm{C}$ in the presence of $2,2^{\prime}$-azobisisobutyronitrile (AIBN) as follows: $R_{\mathrm{p}}=8.08 \times 10^{-4}[\mathrm{TBS}]^{1.39}[\mathrm{AIBN}]^{0.49}$ (in toluene), $R_{\mathrm{p}}=3.05 \times 10^{-3}[\mathrm{TBS}]^{1.17}[\mathrm{AIBN}]^{0.74}$ (in dioxane). Overall activation energies $(E)$ for the polymerizations in toluene and in dioxane were determined as 24.5 and $22.3 \mathrm{kcal} \mathrm{mol}^{-1}$, respectively. The monomer reactivity ratios $\left(r_{1}, r_{2}\right)$ in the copolymerization of TBS $\left(\mathrm{M}_{1}\right)$ with styrene $\left(\mathrm{ST} ; \mathrm{M}_{2}\right)$, and Alfrey-Price $Q, e$ values were determined as follows: $r_{1}=2.78, r_{2}=0.23, Q_{1}=2.54, e_{1}=-0.14$. The heat of fusion and the heat of polymerization for TBS were 6.0 and $14.9 \mathrm{kcal} \mathrm{mol}^{-1}$, respectively.

KEY WORDS Radical Polymerization / 2,4,5-Tribromostyrene / Styrene /

Polymerization Rate Equation / Monomer Reactivity Ratio / Heat of Polymerization /
\end{abstract}

There have been many reports ${ }^{1-9}$ on the relationships between structure and polymerizability of halogen-substituted styrenes. It was reported ${ }^{1}$ that radical propagation rate is due to polar effect which was explained by the use of the Hammett equation.

Poly(bromostyrene)s and its copolymers are particularly interesting because of their flame retarding properties. ${ }^{10,11}$ Thus, a study on homopolymerizability and copolymerizability of bromo-substituted styrenes has been required in recent years. The polymerizations of brominated styrenes were reported by several investigators. Kinoshita and co-workers ${ }^{2,3}$ described the monomer reactivity ratios of $m$ - and $p$-bromo-substituted styrenes at $30^{\circ} \mathrm{C}$ in bulk condition. Cubbon et al..$^{4,5}$ and Koton et $a{ }^{6}{ }^{6}$ reported the monomer reactivity ratios and relation between polymerization time and conversion for dibromostyrene at $30^{\circ} \mathrm{C}$ in bulk condition. However, there have been no reports on the fundamental solution polymerization and solution copolymerization parameters.

Recently, we investigated the polymerizability of $o-, m$-, and $p$-bromostyrenes ( $o$-MBS, $m$-MBS, $p$-MBS) in solvent (toluene) at $60^{\circ} \mathrm{C}$. We found that there is a large difference among overall polymerization rate for the positional isomers. ${ }^{7}$ The order of polymerization rates was $o$-MBS $>m$-MBS $>p$-MBS. This was considered due to the mutual interaction based on polar, steric, and resonance effect of bromogroups in TBS.

Concerning 2,4,5-tribromostyrene (TBS), Cubbon and co-workers ${ }^{4,5}$ reported that homopolymerization behavior, (i.e., relationship between polymerization time and conversion) and monomer reactivity ratios for the copolymerization of TBS with ST in benzene at $30^{\circ} \mathrm{C}$. However there have been few reports on the fundamental parameters related to the homopolymerization of TBS.

This paper describes the radical polymerization of TBS. Overall polymerization rate

\footnotetext{
† To whom all correspondence should be addressed.
} 
equations at $60^{\circ} \mathrm{C}$, and overall activation energies in toluene and in dioxane for TBS are investigated. The effects of solvents for the polymerization are discussed. Monomer reactivity ratios in the copolymerization of TBS with ST in toluene at $60^{\circ} \mathrm{C}$ are calculated and $Q$ and $e$ values for TBS are determined. In addition, the heat of fusion and heat of polymerization for TBS are also measured by DSC-TG.

\section{EXPERIMENTAL}

\section{TBS Monomer}

TBS was synthesized from the reaction of $\beta$-bromoethylbenzene and bromine, according to a method reported by Sera et al. ${ }^{12}$

Tribrominated $\beta$-bromoethylbenzene was synthesized from $\beta$-bromoethylbenzene (BEB) and bromine $(\mathrm{Br})(\mathrm{Br} / \mathrm{BEB}=3.2)$ with $\mathrm{Fe}$ catalyst. TBS was obtained by the dehydrobromination of $\beta$-bromoethyl group with $\mathrm{KOH}$. However, the resulting TBS in this manner contained other positional isomers (2,3,4- and 2,3,6-TBS) and impurities. These isomers and impurities could be removed by recrystallization from methanol. Pure TBS was obtained by recrystallization several times from methanol. It was confirmed by $\mathrm{GC},{ }^{1} \mathrm{H}$ and ${ }^{13} \mathrm{C} \mathrm{NMR}$ data ${ }^{12}$ : yield $48.1 \%$ (based on BEB); purity $99.9 \% ; \mathrm{mp} 66.7-67.4^{\circ} \mathrm{C} ;{ }^{1} \mathrm{H}$ NMR $(\delta$, ppm from TMS in $\left.\mathrm{CDCl}_{3}\right): 7.81,7.76,6.88$, $5.73,5.45 ;{ }^{13} \mathrm{C}$ NMR $(\delta$, ppm from TMS in $\left.\mathrm{CDCl}_{3}\right)$ : $138.10,122.23,133.72,124.21,123.99$, $130.93,133.88,118.35$.

\section{Other Materials}

ST was purified by the usual methods. 2,2'-Azobisisobutyronitrile (AIBN) as an initiator was purified by recrystallization from methanol and chloroform. Toluene and dioxane as solvents were used after distillation.

\section{Homopolymerization and Copolymerization}

Radical homopolymerization and copolymerization were carried out by the same methods as reported previously. ${ }^{7}$ After polymerization, the reaction mixture was poured into a large amount of methanol to precipitate polymers and to remove an unreacted monomer. The polymers were obtained by filtration, washed with methanol and dried in vacuo at $50^{\circ} \mathrm{C}$. The compositions of the copolymers obtained were determined by elemental analysis (for $\mathrm{Br}$ ).

\section{Measurements}

The number-average $\left(M_{n}\right)$ and weightaverage $\left(M_{w}\right)$ molecular weights of the polymers were measured by a gel permeation chromatography (GPC) using the same procedure as reported previously. ${ }^{7}$ The molecular weights calibration curve was available polystyrene standards.

The heats of fusion $\left(\Delta H_{\mathrm{m}}\right)$ and polymerization $\left(-\Delta H_{\mathrm{p}}\right)$ for TBS were measured by DSC-TG under helium gas. ${ }^{13-15}$ DSC-TG measurement was done with Rigaku Thermal Analysis apparatus. The heating rate was $10 \mathrm{~K} \mathrm{~min}^{-1}$ and Indium (In) (mp $156.4^{\circ} \mathrm{C}$, $\Delta H_{\mathrm{m}}=6.79 \mathrm{cal} \mathrm{g}^{-1}$ ) was used as a standard. After measurement, the sample was poured into a large amount of methanol to precipitate the polymer and remove unreacted monomer. The polymer was obtained by filtration and vacuum drying at $50^{\circ} \mathrm{C}$ to calculate the conversion.

$$
\begin{aligned}
& c(\%)=100 b / a \\
&- \Delta H_{\mathrm{p}}\left(\mathrm{kcal} \mathrm{mol}^{-1}\right) \\
&= Q(\mathrm{kcal}) /[0.01 \times a(\mathrm{~g}) \times c(\%)] \\
& \times M\left(\mathrm{~g} \mathrm{~mol}^{-1}\right)
\end{aligned}
$$

where $a$ is the sample weight before measurement, $b$ is the sample weight after measurement, $c$ is the conversion of the sample, $Q$ is the heat at measurement, and $M$ is the molecular weight of TBS. In this case, there is no weight loss of the sample (TBS). 


\section{RESULTS AND DISCUSSION}

\section{Homopolymerization}

The homopolymerization of TBS was performed with AIBN in toluene and dioxane at $60^{\circ} \mathrm{C}$. In toluene, a part of the resulting polymer was precipitated and the polymerization proceeded heterogeneously. However, in dioxane the polymerization proceeded homogeneously throughout. The resulting polymers were colorless powders.

The homopolymerization rate equations of TBS in toluene and dioxane were determined at $60^{\circ} \mathrm{C}$. The dependence of monomer concentration $(m)$ was determined from polymerization rates $\left(R_{\mathrm{p}}\right)$ obtained at various TBS concentrations under a constant AIBN concentration. $R_{\mathrm{p}}$ is the initial rate of polymerization calculated by the slope of initial straight line in time-conversion curves under various conditions.

Relations between $\log R_{\mathrm{p}}$ and $\log [\mathrm{TBS}]$ are shown in Figure 1. The order $(m)$ with respect to monomer concentration was determined

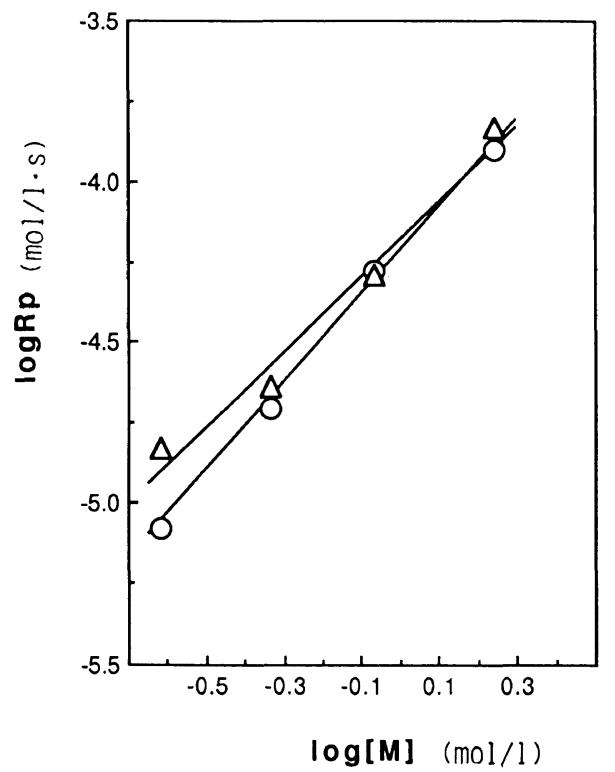

Figure 1. Effects of the monomer concentration on the rate of polymerization for TBS in toluene $(O)$ and dioxane $(\triangle)$ at $60^{\circ} \mathrm{C}\left([\mathrm{AIBN}]=4.61 \mathrm{mmol}^{-1}\right)$. as $1.39 \pm 0.11$ in toluene and $1.17 \pm 0.13$ in dioxane from the slope of these lines. Polymerization proceeded heterogeneously in toluene and homogeneously in dioxane. The value of $m(=1.17)$ in dioxane was slightly higher than 1 even in the homogeneous polymerization system, which agreed with the behavior of monobrominated styrenes in toluene. $^{7}$

The reaction order $(n)$ with respect to AIBN concentration was obtained from the polymerizations of TBS at various AIBN concentrations under a constant TBS concentration. Relations between $\log R_{\mathrm{p}}$ and $\log$ [AIBN] are shown in Figure 2. The observed $n$ values in toluene $(0.49 \pm 0.04)$ almost satisfied the ordinary $1 / 2$ power rule, but the value of $n$ in dioxane $(0.74 \pm 0.08)$ was fairly high. This behavior $(n>0.5)$ was observed even at homogeneous polymerization. Dioxane as a solvent may play an important role in the dependence of AIBN concentration.

The polymerizations of ST were performed under the same conditions as TBS. The values

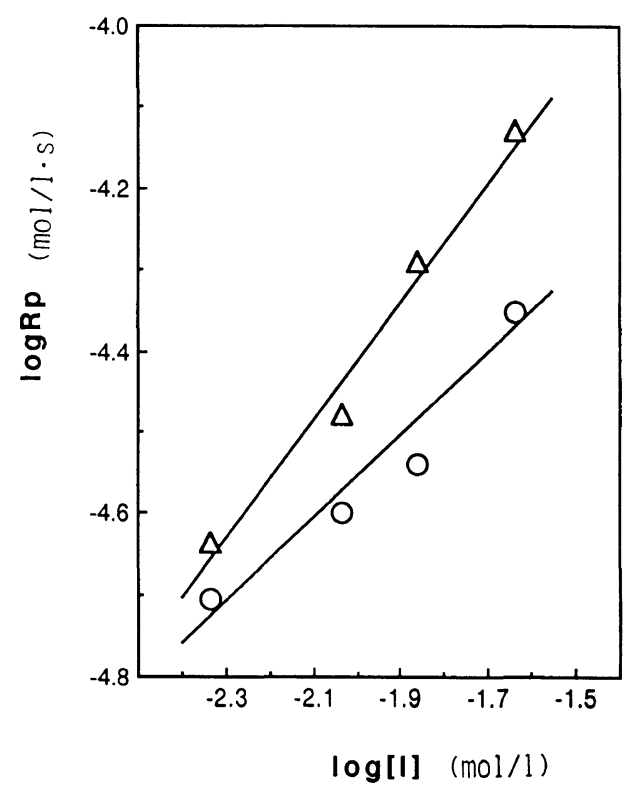

Figure 2. Effects of the AIBN concentration on the rate of polymerization for TBS in toluene $(O)$ and dioxane $(\triangle)$ at $60^{\circ} \mathrm{C}\left([\mathrm{TBS}]=0.461 \mathrm{~mol} \mathrm{l}^{-1}\right)$. 
for $m$ and $n$ were determined as almost 1.0 and 0.5 , respectively. That is, there was difference between TBS and ST with respect to the values for $m$ (in toluene) and $n$ (in dioxane). The reason for this cannot be easily explained, but may be attributed to the solubility of the resulting polymers in the solvents.

The polymerization rate equations of TBS in toluene and in dioxane at $60^{\circ} \mathrm{C}$ are shown as follows:

In toluene:

$$
R_{\mathrm{p}}=8.08 \times 10^{-4}[\mathrm{TBS}]^{1.39}[\mathrm{AIBN}]^{0.49}
$$

In dioxane:

$$
R_{\mathrm{p}}=3.05 \times 10^{-3}[\mathrm{TBS}]^{1.17}[\mathrm{AIBN}]^{0.74}
$$

Figure 3 shows the relation between $\log k$

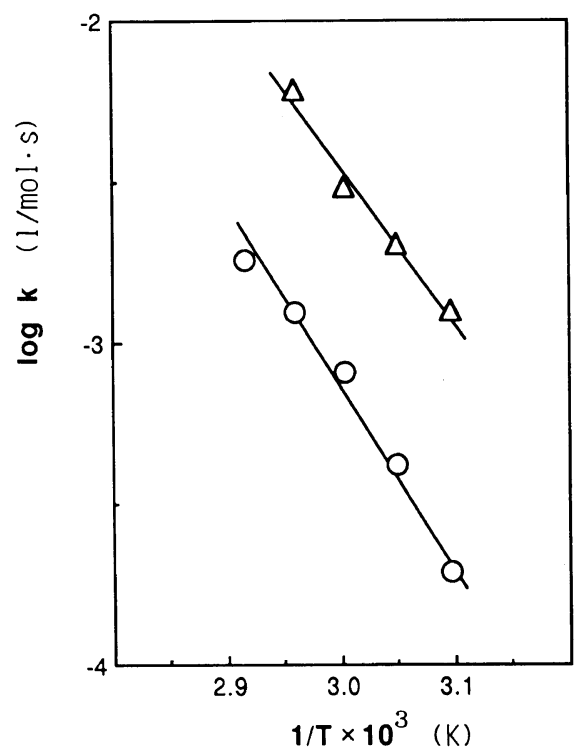

Figure 3. Relationship between $\log k$ and $1 / T$ for polymerization of TBS $\left([\mathrm{TBS}]=0.461 \mathrm{~mol} \mathrm{l}^{-1}\right)$ initiated by AIBN $\left([\mathrm{AIBN}]=4.61 \mathrm{mmol}^{-1}\right)$ in toluene $(\mathrm{O})$ and dioxane $(\triangle)$. and $1 / T$. Overall activation energies $(E)$ for the polymerization of TBS in toluene and in dioxane were 24.5 and $22.3 \mathrm{kcal} \mathrm{mol}^{-1}$, respectively. These values are similar to those for ST $\left(24.5 \mathrm{kcal} \mathrm{mol}^{-1}\right.$ in toluene and $25.5 \mathrm{kcal} \mathrm{mol}^{-1}$ in dioxane, as calculated from the polymerizations of ST under the same conditions as TBS).

The homopolymerization parameters of TBS are summarized in Table I. The rate constants at $60^{\circ} \mathrm{C}$ for ST were determined as $2.44 \times 10^{-5} 1$ $\mathrm{mol}^{-1} \mathrm{~s}^{-1}$ (toluene) and $3.61 \times 10^{-5} 1 \mathrm{~mol}^{-1} \mathrm{~s}^{-1}$ (dioxane), respectively, from the polymerizations of ST under the same conditions as TBS. The rate constants for TBS were much larger than those for ST, as shown in Table $I$. Difference may be attributable to polar and resonance effects rather than steric hindrance of three bromo-groups in TBS.

\section{Copolymerization}

The copolymerization of TBS $\left(\mathrm{M}_{1}\right)$ and ST $\left(\mathrm{M}_{2}\right)$ was performed in toluene at $60^{\circ} \mathrm{C}$ using AIBN as the initiator. Polymerization was stopped within $20 \%$ yield of the polymer in order to calculate monomer reactivity ratios. All copolymerizations proceeded homogeneously throughout.

The copolymer-composition curve is shown in Figure 4. Monomer reactivity ratios were determined according to the high conversion method reported by Kelen-Tüdös, ${ }^{16}$ and Alfley-Price ${ }^{17} Q_{1}$ and $e_{1}$ values were calculated assuming $Q_{2}=1.0$ and $e_{2}=-0.8$ for ST. These copolymerization parameters are shown in Table II, and compared with those for monobrominated styrene. The values $r_{1}$ and $1 / r_{2}$ are 2.78 and 4.35 , respectively. Therefore,

Table I. Parameters of polymerization rate equations $\left(R_{\mathrm{p}}\right)$, overall activation energies $(E)$ and

\begin{tabular}{|c|c|c|c|c|c|}
\hline \multirow{2}{*}{ Solvent } & \multicolumn{3}{|c|}{$R_{\mathrm{p}}=k[\mathrm{TBS}]^{m}[\mathrm{AIBN}]^{n}\left(60^{\circ} \mathrm{C}\right)$} & \multirow{2}{*}{$\frac{E}{\mathrm{kcal} \mathrm{mol}^{-1}}$} & \multirow{2}{*}{$\begin{array}{c}A \\
s^{-1}\end{array}$} \\
\hline & $m$ & $n$ & $k\left(1 \mathrm{~mol}^{-1} \mathrm{~s}^{-1}\right)$ & & \\
\hline Toluene & $1.39 \pm 0.11$ & $0.49 \pm 0.04$ & $8.08 \times 10^{-4}$ & 24.5 & $7.80 \times 10^{12}$ \\
\hline Dioxane & $1.17 \pm 0.13$ & $0.74 \pm 0.08$ & $3.05 \times 10^{-3}$ & 22.3 & $1.41 \times 10^{12}$ \\
\hline
\end{tabular}
frequency factors $(A)$ for 2,4,5-tribromo styrene (TBS) 
Table II. Monomer reactivity ratios and $Q_{1}, e_{1}$ values for brominated styrenes $\left(\mathrm{M}_{1}\right)$ and styrene $\left(\mathrm{M}_{2}\right)^{\mathrm{a}}$

\begin{tabular}{|c|c|c|c|c|c|c|c|}
\hline $\mathrm{M}_{1}$ & $r_{1}$ & $r_{2}$ & $1 / r_{2}$ & $Q_{1}$ & $e_{1}$ & $\frac{\text { Temp }}{{ }^{\circ} \mathrm{C}}$ & Ref \\
\hline TBS & 2.78 & 0.23 & 4.35 & 2.54 & -0.14 & 60 & This work \\
\hline TBS & 0.60 & 0.05 & 20.0 & $\begin{array}{l}(4.47) \\
(89.5)\end{array}$ & $\begin{array}{r}(1.07) \\
(-2.67)\end{array}$ & 30 & 5 \\
\hline$o$-Bromostyrene & 1.31 & 0.55 & 1.82 & 1.15 & -0.22 & 60 & 7 \\
\hline$m$-Bromostyrene & 1.22 & 0.64 & 1.56 & 1.05 & -0.30 & 60 & 7 \\
\hline$p$-Bromostyrene & 0.79 & 0.59 & 1.69 & 0.84 & 0.08 & 60 & 7 \\
\hline
\end{tabular}

a ( ): calculated from $r_{1}=0.60, r_{2}=0.05$ by us.

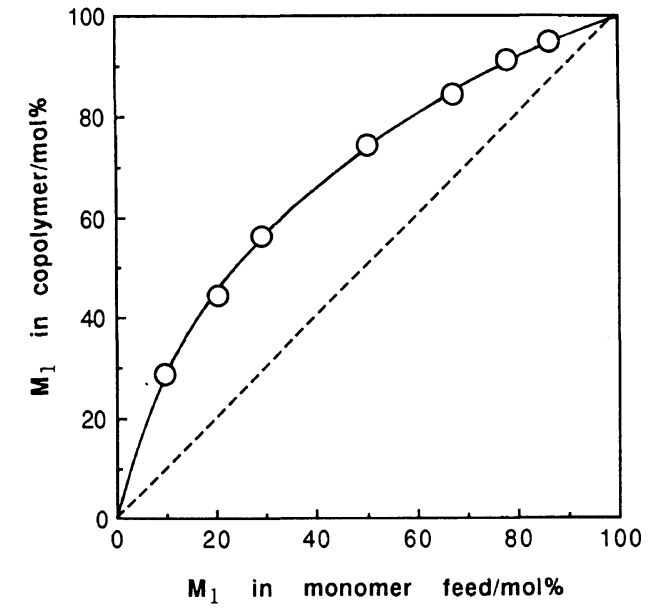

Figure 4. Copolymer composition curves of TBS $\left(\mathrm{M}_{1}\right)$ and $\mathrm{ST}\left(\mathrm{M}_{2}\right)$ in toluene at $60^{\circ} \mathrm{C}\left([\mathrm{AIBN}]=8.8 \mathrm{mmol}^{-1}\right)$.

monomer reactivity of TBS is much larger than that of ST. The $Q_{1}(=2.54)$ and $e_{1}(=-0.14)$ values of TBS are larger than those of ST. This may be understood from the fact that three substituted bromo-groups increase both resonance stability and electron attraction. Cubbon et al. ${ }^{5}$ reported the monomer reactivity ratios $\left(r_{1}=0.60, r_{2}=0.05\right.$, as shown in Table II) from the results of bulk copolymerizations of TBS $\left(\mathrm{M}_{1}\right)$ with $\mathrm{ST}\left(\mathrm{M}_{2}\right)$ at $30^{\circ} \mathrm{C}$. Using these values, $Q_{1}$ and $e_{1}$ values were calculated to be as follows: $Q_{1}=4.47, e_{1}=1.07 ; Q_{1}=89.5$, $e_{1}=-2.67$. These values were abnormally large, as compared with ours (Table II). In the

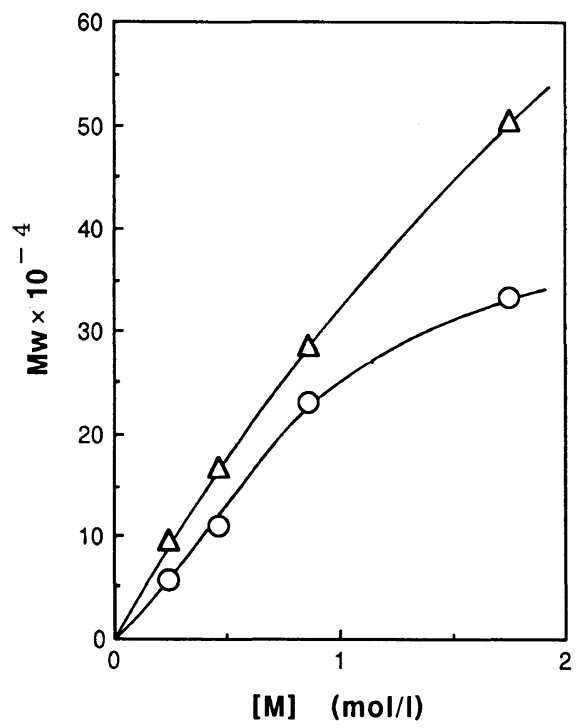

Figure 5. Effects of the monomer concentration on molecular weight $\left(M_{w}\right)$ for poly(TBS) $([\mathrm{AIBN}]=4.61$ mmol $\left.1^{-1}\right)$. $O$, obtained in toluene; $\triangle$, obtained in dioxane.

solution polymerization, the relative reactivity of TBS monomer by an attack of a polystyryl radical $\left(1 / r_{2}=4.35\right)$ was much lower than that $\left(1 / r_{2}=20.0\right)$ in the bulk copolymerization. Thus, copolymerization reactivity is much influenced by the polymerization temperature and solvent.

\section{Molecular Weights of Homopolymers}

Figure 5 shows the relation between 
T. Oishi, H. Horie, and H. ShuYama

Table III. Thermal behavior of 2,4,5-tribromostyrene (TBS)

\begin{tabular}{|c|c|c|c|c|c|c|}
\hline \multirow{2}{*}{$\begin{array}{l}\text { Run } \\
\text { No. }\end{array}$} & Sample weight & $\mathrm{mp}$ & $\Delta H_{\mathrm{m}}$ & $T_{\mathrm{c}}$ & $-\Delta H_{\mathrm{p}}$ & Conversion \\
\hline & $\mathrm{mg}$ & ${ }^{\circ} \mathrm{C}$ & $\mathrm{kcal} \mathrm{mol}^{-1}$ & ${ }^{\circ} \mathrm{C}$ & $\mathrm{kcal} \mathrm{mol}^{-1}$ & $\%$ \\
\hline 1 & 21.3 & 66 & 5.8 & & & \\
\hline 2 & 22.0 & 66 & 6.1 & & & \\
\hline 3 & 20.5 & & & 158 & 14.9 & 77.0 \\
\hline 4 & 20.7 & & & 158 & 14.9 & 80.0 \\
\hline Average & & 66 & 6.0 & 158 & 14.9 & \\
\hline
\end{tabular}

monomer concentrations in the polymerizations and weight-average molecular weights $\left(M_{w}\right)$ of the resulting polymers. $M_{w}$ increased with monomer concentration. The polydispersities $\left(M_{w} / M_{n}\right)$ of the polymers were 1.28 to 1.58 . When the polymerizations proceeded in toluene, $M_{w}$ hardly increased at high monomer concentration. $M_{w}$ increased at high TBS monomer concentration in dioxane. $M_{w}$ and $M_{w} / M_{n}$ of the copolymers were $1.8 \times 10^{4}$ $8.0 \times 10^{4}$ and $1.3-1.8$, respectively.

\section{Heats of Fusion and Polymerization}

The heats of polymerization $\left(-\Delta H_{\mathrm{p}}\right)$ for volatile monomers such as ST can be obtained by directly measuring the heat evolved when the polymerization reaction is allowed to take place in a calorimeter. ${ }^{18}$ The heat of polymerization can also be obtained indirectly as the difference between the heat of combustion for a liquid monomer and that for a solid polymer. $^{19}$

Measurement of the $-\Delta H_{\mathrm{p}}$, the ceiling temperature $\left(T_{\mathrm{c}}\right)$, heat of fusion $\left(\Delta H_{\mathrm{m}}\right)$, and melting point for TBS were measured according to the procedure reported by Yuki et $a .^{13-15} T_{\mathrm{c}}$ is defined as the temperature for reaching equilibrium between the propagation and depropagation rates. Therefore, the polymerization is essentially terminating.

DSC-TG curves and the results of measurements are shown in Figure 6 and Table III, respectively. $-\Delta H_{\mathrm{p}}$ for TBS $(=14.9 \mathrm{kcal}$ $\mathrm{mol}^{-1}$ ) was lower $1-2 \mathrm{kcal} \mathrm{mol}^{-1}$ than that

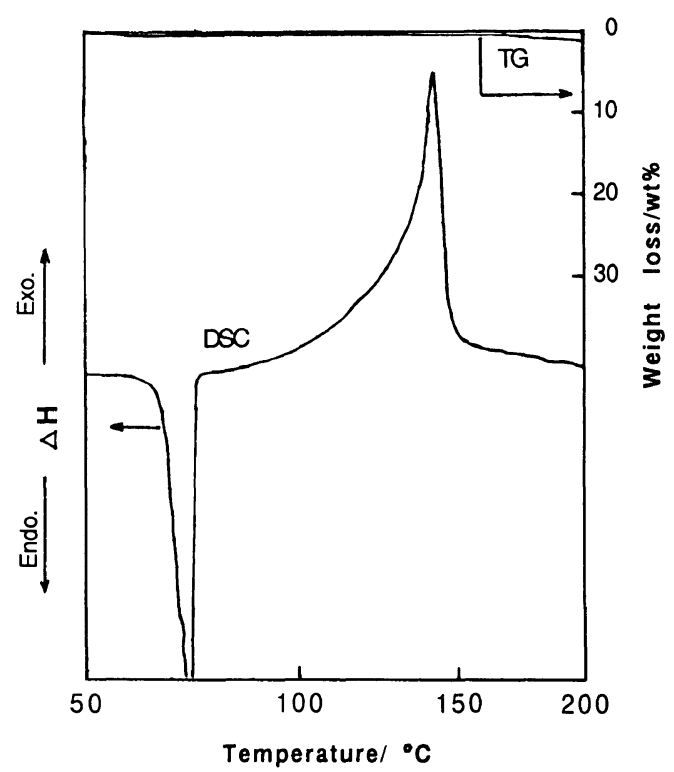

Figure 6. TG-DSC curves of TBS.

for ST. The $T_{\mathrm{c}}\left(=158^{\circ} \mathrm{C}\right)$ was lower than those for ordinary vinyl monomers. ${ }^{18-20}$ As a rule, $-\Delta H_{\mathrm{p}}$ decreases with lowering the $T_{\mathrm{c}}$. For example, $T_{\mathrm{c}}$ and $-\Delta H_{\mathrm{p}}$ of $\alpha$-methyl styrene are $63^{\circ} \mathrm{C}$ and $8.4 \mathrm{kcal} \mathrm{mol}^{-1}$, respectively. $-\Delta H_{\mathrm{p}}$ of TBS implies rather lower value, which can be understood from the fact that $-\Delta H_{\mathrm{p}}$ decreases with lowering $T_{c}$, as described above. $H_{\mathrm{m}}$ of TBS was determined as $6.0 \mathrm{kcal} \mathrm{mol}^{-1}$.

\section{CONCLUSIONS}

1. Radical polymerizations of TBS were carried out with AIBN in toluene and dioxane. 
The overall polymerization rate equations at $60^{\circ} \mathrm{C}$ are as follows:

$$
\begin{aligned}
R_{\mathrm{p}}= & 8.08 \times 10^{-4}[\mathrm{TBS}]^{1.39}[\mathrm{AIBN}]^{0.49} \\
& \quad(\text { in toluene) } \\
R_{\mathrm{p}}= & 3.05 \times 10^{-3}[\mathrm{TBS}]^{1.17}[\mathrm{AIBN}]^{0.74} \\
& \quad \text { (in dioxane) }
\end{aligned}
$$

2. Overall activation energies for the polymerization of TBS in toluene and in dioxane were obtained as 24.5 and $22.3 \mathrm{kcal}$ $\mathrm{mol}^{-1}$, respectively.

3. From the results of the radical copolymerizations of TBS $\left(M_{1}\right)$ with ST $\left(M_{2}\right)$ in toluene at $60^{\circ} \mathrm{C}$, monomer reactivity ratios were determined as follows: $r_{1}=2.78, r_{2}=0.23$ and $Q_{1}=2.54, e_{1}=-0.14$.

4. The heats of fusion and polymerization were obtained as $6.0 \mathrm{kcal} \mathrm{mol}^{-1}$ and $14.9 \mathrm{kcal}$ $\mathrm{mol}^{-1}$, respectively.

\section{REFERENCES}

1. M. Imoto, M. Kinoshita, and M. Nishigaki, Makromol. Chem., 86, 217 (1965).

2. M. Kinoshita and M. Nishigaki, Kogyo Kagaku Zasshi, 72, 2332 (1969).

3. M. Kinoshita and M. Imoto, Kogyo Kagaku Zasshi, 68, 2454 (1965).

4. R. C. P. Cubbon and J. D. B. Smith, Polymer, 10,
479 (1969).

5. R. C. P. Cubbon and J. D. B. Smith, Polymer, 10, 489 (1969).

6. M. M. Koton, T. M. Kiselva, and F. S. Florinsky, J. Appl. Chem. USSR, 26, 625 (1953).

7. H. Horie, H. Shuyama, and T. Oishi, Polym. J., 25, 757 (1993).

8. C. Walling, E. R. Briggs, K. B. Wolfstrin, and F. R. Mayo, J. Am. Chem. Soc., 70, 1537 (1948).

9. C. Walling, E. R. Briggs, K. B. Wolfstrin, and F. R. Mayo, J. Am. Chem. Soc., 70, 1543 (1948).

10. D. Alsheh and G. Marom, J. Appl. Polym. Sci., 22, 3177 (1978).

11. S. K. Brauman, J. Fire Retard. Chem., 7, 130 (1980).

12. T. Sera, Y. Mabuchi, H. Inoue, Y. Oda, T. Okada, and H. Toita, Nippon Kagaku Kaishi, 633 (1992).

13. Y. Yuki and T. Ouchi, Kobunshi Ronbunshu, 32, 97 (1975).

14. Y. Yuki and T. Ouchi, Kobunshi Ronbunshu, 33, 303 (1976).

15. Y. Yuki, H. Kunisada, T. Seo, and T. Kakurai, Kobunshi Ronbunshu, 40, 733 (1983).

16. F. Tüdös, T. Kelen, T. F. Berzsnich, and B. Turcsanyi, J. Macromol. Sci. Chem., A10, 1513 (1976).

17. T. Alfrey, Jr. and C. C. Price, J. Polym. Sci., 2, 101 (1947).

18. L. K. J. Tong and W. O. Kenyon, J. Am. Chem. Soc., 69, 1402 (1947).

19. D. E. R. Roberts, W. W. Walton, and R. S. Jessup, J. Polym. Sci., 65, 1432 (1943).

20. W. K. Busfield, "Heats and Entropies of Polymerization, Ceiling Temperature", in "Polymer Hand Book," 3rd ed, J. Brandrup and E. H. Immergut, Ed., Wiley, New York, N.Y., 1989, pp 11-297. 